\title{
IUFOST2006/1396 The Status and Progress on Food Safety in China
}

\author{
X. Shi \\ Dept. Food Sci \& Tech and Bor Luh Food Safety Center, Shanghai Jiao Tong University, 2678 Qixin Rd, \\ 201101 Shanghai, China \\ xmshi@sjtu.edu.cn
}

In recent years, unprecedented attention has been paid by the government and people on the status and progress on food safety in China as the great development occurred in economy and society. Chinese government has made great efforts to adjust regulatory mechanism on food safety managements. In April 2003, the State Departments made a resolution to found the State Food and Drug Administration (SFDA), and the regulatory meeting mechanism was established. SFDA has responsibilities to organize the ministerial meeting on food safety managements. Meanwhile, rational readjustment on responsibilities and intendance extents of related departments was made based on the principle that each department supervises certain sub-sectors or stages in food chains (such as planting and breeding, processing, circulation and consumption). A principium pattern of food safety control system has been established in recent years in China, in which the central government is responsible for leading and regulation, local government for case managements, actions by all related governmental departments, and consequently the administration and disposal efficiency for food safety has been highly enhanced. The law, regulation and standard systems on food safety have been established and improved in China. As a result of the adjustments for regulatory functions of government departments, the "Agricultural Product Quality and Safety Law of the People's Republic of China" was approved legally on April 29, 2006, and will be implemented since November 1, 2006. 'Food Safety Law' has been involved in the legislative plan, and hopefully it will be promulgated in December 2006. Meanwhile, a series of individual regulations and standards on food safety have been revised and released in accordance with the requirements of the CAC, and a basic law, regulation and standard system framework on food safety has been established in China. The capacity on technology research and development for food safety has enhanced, and the inspection, evaluation and risk assessment system on food safety has been improved. In recent years, a number of research projects on food safety, such as 'State major special technology project on food safety', were initiated to improve testing and monitoring techniques on food safety. These research projects are focused on the key technologies and related equipments for testing and monitoring food borne pathogens and chemicals response to the urgent need of systematic control of food borne hazards. China's first food-pollutants-monitoring-network covering 13 provinces and municipalities has also been established. This means that a great progress has been made on food safety risk assessment in China. 